\title{
COMPARISON OF OUTCOMES BETWEEN THE LICHTENSTEIN AND BASSINI METHODS IN INGUINAL HERNIA- A RANDOMISED CONTROLLED TRIAL
}

\author{
Milad Habibi Gatabi', Ali Asghar Darzi², Emad Moudi ${ }^{3}$
}

1MD, Student Research Committee, School of Medicine, Babol University of Medical Sciences, Babol, Iran.

${ }^{2}$ Associate Professor, Department of Surgery, Babol University of Medical Sciences, Babol, Iran.

3MD, Clinical Research Development Centre, Shahid Beheshti Hospital, Babol University of Medical Sciences, Babol, Iran.

\section{ABSTRACT}

\section{BACKGROUND}

Inguinal hernia is one of the most common causes of abdominal surgery, especially in males. For repairing this kind of hernia, there are laparoscopic and open surgical methods. Open surgery may be done through the Lichtenstein (with mesh) and Bassini (without mesh) techniques.

In the present study we compared the outcomes between the Lichtenstein and Bassini's methods in Babol, northern Iran.

\section{MATERIALS AND METHODS}

This prospective randomised controlled trial study was performed on male patients aged 18 - 80 years old with one-sided inguinal hernia, who were candidates for surgery during 2015 and 2016. The subjects were randomly assigned into two groups of Lichtenstein $(n=70)$ and Bassini $(n=50)$. Postoperative complications of the two groups were noted in a checklist. Visual Analogue Scale (VAS) was used to assess the severity of post-operative pain. Data was analysed with SPSS software.

\section{RESULTS}

The mean hospitalisation duration, time to get back to work and acute pain duration were $1.00 \pm 0.00,16.70 \pm 13.48$ and $8.80 \pm 7.53$ days in Lichtenstein group compared with $1.10 \pm 0.36,19.12 \pm 11.89$ and $8.06 \pm 6.81$ days in Bassini group. Mean chronic pain duration was $4.50 \pm 071$ months in Lichtenstein group versus $7.00 \pm 3.87$ months in Bassini group. No significant differences were found in the post-operative complications between the two groups. Post-operative acute and chronic pains were observed in $28.6 \%$ and $36 \%$ of Lichtenstein subjects in comparison to $36 \%$ and $10 \%$ of Bassini subjects. Haematoma $(n=2)$ and infection (n=1) were seen only in Lichtenstein group. Urinary retention $(n=1)$ and hernia on the opposite side $(n=2)$ were found only in Bassin $\mathrm{i}$ group. Based on VAS pain, mean severity of pain in Lichtenstein group was $0.29 \pm 0.46$, significantly less than in Bassini group which was $0.60 \pm 0.81(\mathrm{p}=0.024)$.

\section{CONCLUSION}

The results showed that the outcomes of Lichtenstein and Bassini's methods were highly similar. Therefore, both techniques were considered to be safe for the patients.

\section{KEY WORDS}

Lichtenstein, Inguinal Hernia, Post-Operative Complications.

HOW TO CITE THIS ARTICLE: Gatabi MH, Darzi AA, Moudi E. Comparison of outcomes between the Lichtenstein and Bassini methods in inguinal hernia- a randomised controlled trial. J. Evolution Med. Dent. Sci. 2018;7(42):4505-4509, D0I: $10.14260 /$ jemds/2018/1005

\section{BACKGROUND}

Inguinal hernia is one of the most common general surgeries. Its prevalence in men is seven-fold higher than in women and increases with age, especially after 40 years old. The most common form of hernia in both sexes is indirect. Inguinal hernia more frequently occurred on right side than on left side and should be treated after the diagnosis.(1-4)

Inguinal hernia not only causes malaise, pain and dysfunction in the patients, but also can lead to problems in terms of beauty for them.(5) Complications of inguinal hernia are importantly dangerous, which mostly occur following

'Financial or Other Competing Interest': None.

Submission 01-09-2018, Peer Review 27-09-2018,

Acceptance 03-10-2018, Published 15-10-2018.

Corresponding Author:

Dr. Emad Moudi

Department of Urology,

Babol University of Medical Sciences,

Ganjafrooz Street, Babol, Mazandaran,

Iran.

E-mail: emadmoudi@gmail.com

DOI: $10.14260 /$ jemds $/ 2018 / 1005$

\section{(c) $($ ) $\$$}

incarceration and need urgent attention and treatment measures. ${ }^{(6,7)}$ These complications include obstruction, ischaemia and gangrene of the bowel or any incarceration in the hernia sack. $(6,8)$ Overall, most of the inguinal hernias should be repaired by surgery after the diagnosis through different methods based on patient's age and the surgeon's skill.(9) Also repairing the inguinal hernia is easy, but many cases face recurrence and more precise techniques and expertise are needed for surgeons. In the present study, we aimed to compare the rates of post-operative complications and recurrence between the Lichtenstein's tension free mesh hernioplasty and Bassini's repair and finally report the method with less complications.

\section{MATERIALS AND METHODS}

\section{Locations and Participants}

This prospective randomised controlled trial was conducted on male patients aged 18 - 80 years old with diagnosis of unilateral inguinal hernia who underwent surgery between March 2015 and August 2016. The diagnosis of hernia was made through physical examination. The operations were done in Shahid Beheshti and Ayatollah Rohani teaching 
hospitals. Patients with history of hernia surgery, bilateral hernia, incarcerated hernia and femoral hernia were excluded from the study.

\section{Randomisation}

The purpose and protocol of the study was explained to the patients. The subjects consented to participate were randomly divided into two groups using a computergenerated random number table: 1) Patients who underwent Lichtenstein's repair; 2) Patients who underwent Bassini's repair. The allocations were concealed in consecutively numbered and sealed envelopes.

\section{Sample Size Calculation}

The sample size was estimated as at least 50 patients in each group by a non-inferiority margin of $\delta=-0.12$ that was based on clinical judgement with $80 \%$ power and type I error rate of $5 \%$. Furthermore, the proportion of the study outcome (=rate of patients experiencing post-operative chronic pain) in Lichtenstein and Bassini groups was considered as $2.5 \%$ and $5 \%$

\section{Data Collection}

The necessary data were collected from the subjects by a checklist including age, education (illiterate, lower diploma, diploma, higher diploma), occupation (free, retired, farmerworker-businessman-driver-shopkeeper, teacher-employeestudent), smoking (Yes/No), opioid (Yes/No), analgesic (Yes/No), method of repairing, duration of surgery, hospitalisation duration, post-operative complications (haematoma, urinary retention, headache, infection, opposite-side inguinal hernia, acute and chronic pains, recurrence, dysuria, testicular pain and pain during intercourse), acute pain duration, chronic pain duration and time to return to work. Chronic pain was defined as the persistent pain lasting at least 3 months postoperatively.(10,11) The severity of post-operative pain was evaluated by Visual Analogue Scale (VAS).(12) VAS pain scale ranges from 0 (without pain) to 10 (severe pain) scores. The patients were followed-up for six months. Examinations of the patients were done by the surgeon.

\section{Surgical Procedure}

Spinal anaesthesia was induced in all patients. To access the hernia site for herniorrhaphy, the skin was incised obliquely above the hip inguinal. After opening the superficial layers of skin, aponeurosis of the external abdominal oblique muscle was opened and the cord was then released. In Bassini's method, to repair the floor of the inguinal canal, conjoint tendon was sutured into the inguinal ligament with polypropylene ' 1 ' interrupted sutures. In Lichtenstein method, mesh was placed on the defect and fixed to the internal ring laterally and to the pubic tubercle anteriorly.

\section{Statistical Analysis}

The SPSS software was used for statistical analysis. The data underwent descriptive analysis to determine the frequency, percentage, mean and standard deviation. Chi-square and independent t-test were used to compare qualitative and quantitative variables, respectively, between the two groups of Bassini and Lichtenstein. P-value less than 0.05 was considered as significant.

\section{Ethical Issues}

The informed written consent was obtained from each subject. The patients' information was kept confidential. This study was approved by the Ethical Research Committee of Babol University of Medical Sciences. This trial was registered in the Iranian Registry of Clinical Trials with the number IRCT2016042627608N1.

\section{RESULTS}

A total of 136 patients were initially enrolled for surgery because of inguinal hernia. Three patients with incarcerated hernia and 13 patients with history of hernia surgery were excluded. Therefore, 120 patients were finally included in the study with mean age of $53.61 \pm 15.85$ years old. Twenty eight patients $(23.3 \%)$ had direct hernia, $83(69.2 \%)$ had indirect hernia and $9(7.5 \%)$ had sliding hernia. The subjects were randomly divided into two groups. Groups I (Lichtenstein repair) and II (Bassini's repair) had 70 and 50 patients, respectively. There was no loss to follow-up during the study. The CONSORT flow-diagram of the participants is indicated in Figure 1.(13) The baseline and surgical characteristics of the subjects are shown in Table 1. No significant differences were found between the two groups in terms of the variables.

The total post-operative complications during hospitalisation were haematoma in 2 patients, urinary retention in 1 patient and headache in 2 patients. No any significant differences were observed between the two groups in terms of these complications (Table 2).

The complications seen after the hospital discharge were infection in 1 patient, opposite-side inguinal hernia in 2 patients, acute pain in 38 patients and chronic pain in 7 patients. No recurrence was found in any patients. There was no significant difference between the two groups in terms of these complications (Table 3). Other post-operative complications included inguinal pain and dysuria which were seen in 2 and 3 patients, respectively. Testicular pain and pain during intercourse were not complained by any patients. As shown in Table 3, no significant difference was observed between the two groups in terms of these complications. These complications healed with antibiotics and/or nonsteroid analgesic. The opposite-side inguinal hernia was treated by surgery.

Based on VAS pain, the mean severity of pain in Group I was $0.29 \pm 0.46$, significantly less than in Group II which was $0.60 \pm 0.81(\mathrm{p}=0.024)$.

\begin{tabular}{|c|c|c|c|}
\hline Variables & $\begin{array}{c}\text { Lichtenstein } \\
\text { Group }(n=70, \%) \\
\end{array}$ & $\begin{array}{c}\text { Bassini Group } \\
(\mathrm{n}=50, \%)\end{array}$ & $\begin{array}{c}\text { P- } \\
\text { value }\end{array}$ \\
\hline $\begin{array}{l}\text { Age (Years old, } \\
\text { Mean } \pm \text { SD) }\end{array}$ & $52.20 \pm 15.95$ & $55.58 \pm 15.64$ & 0.251 \\
\hline \multicolumn{4}{|l|}{ Residence } \\
\hline Urban & $38(54.3)$ & $18(36)$ & \multirow{2}{*}{0.063} \\
\hline Rural & $32(45.7)$ & $32(64)$ & \\
\hline \multicolumn{4}{|l|}{ Education } \\
\hline Illiterate & $16(22.9)$ & $15(30)$ & \multirow{4}{*}{0.711} \\
\hline Under Diploma & $23(32.9)$ & $12(24)$ & \\
\hline Diploma & $19(27.1)$ & $14(28)$ & \\
\hline Upper Diploma & $12(17.1)$ & $9(18)$ & \\
\hline \multicolumn{4}{|l|}{ Occupation } \\
\hline Self-employment & $17(24.3)$ & $17(34)$ & \multirow[b]{3}{*}{0.604} \\
\hline Retired & $6(8.6)$ & $4(8)$ & \\
\hline $\begin{array}{l}\text { Farmer, worker, } \\
\text { businessman, } \\
\text { driver, shopkeeper }\end{array}$ & 39 (55.7) & $22(44)$ & \\
\hline
\end{tabular}




\begin{tabular}{|c|c|c|c|}
\hline $\begin{array}{c}\text { Teacher, Employee, } \\
\text { Student }\end{array}$ & $8(11.4)$ & 7 (14) & \\
\hline \begin{tabular}{|c|} 
Body Mass Index \\
$\left(\mathrm{kg} / \mathrm{m}^{2}\right.$, \\
Mean \pm SD)
\end{tabular} & $25.20 \pm 3.21$ & $25.73 \pm 3.17$ & 0.380 \\
\hline Smoking & & & \\
\hline Yes & $11(15.7)$ & $6(12)$ & \multirow{2}{*}{0.608} \\
\hline No & $59(84.3)$ & $44(88)$ & \\
\hline Opioid & & & \\
\hline Yes & $11(15.7)$ & $3(6)$ & \multirow{2}{*}{0.198} \\
\hline No & 59 (84.3) & $47(94)$ & \\
\hline Analgesic & & & \\
\hline Yes & $10(14.3)$ & $6(12)$ & \multirow{2}{*}{0.791} \\
\hline No & $60(85.7)$ & $44(88)$ & \\
\hline \begin{tabular}{|c|} 
Duration of \\
Surgery (minutes, \\
Mean $\pm S D$ )
\end{tabular} & $54.14 \pm 24.82$ & $59.00 \pm 18.52$ & 0.222 \\
\hline $\begin{array}{c}\text { Hospitalisation } \\
\text { duration (days, } \\
\text { Mean } \pm \text { SD) }\end{array}$ & $1.00 \pm 0.00$ & $1.10 \pm 0.36$ & 0.058 \\
\hline $\begin{array}{c}\text { Time to get back to } \\
\text { work (days, } \\
\text { Mean } \pm \text { SD) }\end{array}$ & $16.70 \pm 13.48$ & $19.12 \pm 11.89$ & 0.311 \\
\hline $\begin{array}{c}\text { Acute pain } \\
\text { duration (days, } \\
\text { Mean } \pm S D \text { ) }\end{array}$ & $8.80 \pm 7.53$ & $8.06 \pm 6.81$ & 0.933 \\
\hline \begin{tabular}{|c|} 
Chronic pain \\
duration (months, \\
Mean $\pm S D$ )
\end{tabular} & $4.50 \pm 071$ & $7.00 \pm 3.87$ & 0.558 \\
\hline
\end{tabular}

\begin{tabular}{|c|c|c|c|}
\hline Variables & $\begin{array}{c}\text { Lichtenstein Group } \\
(\mathbf{n = 7 0 ,} \mathbf{0})\end{array}$ & $\begin{array}{c}\text { Bassini Group } \\
\mathbf{( n = 5 0 , \% )}\end{array}$ & $\begin{array}{c}\text { P- } \\
\text { value }\end{array}$ \\
\hline Haematoma & $2(2.9)$ & $0(0)$ & 0.228 \\
\hline $\begin{array}{c}\text { Urinary } \\
\text { Retention }\end{array}$ & $0(0)$ & $1(2)$ & 0.235 \\
\hline Headache & $1(1.4)$ & $1(2)$ & 0.810 \\
\hline
\end{tabular}

Table 2. Post-Operative Complications during Hospitalisation

\begin{tabular}{|c|c|c|c|}
\hline Variables & $\begin{array}{c}\text { Lichtenstein Group } \\
(n=70, \%)\end{array}$ & \begin{tabular}{|c|} 
Bassini Group \\
$(\mathrm{n}=50, \%)$
\end{tabular} & $\begin{array}{c}\text { P- } \\
\text { value }\end{array}$ \\
\hline Infection & $1(1.4)$ & $0(0)$ & 0.396 \\
\hline Recurrence & $0(0)$ & $0(0)$ & $\mathrm{NA}^{*}$ \\
\hline $\begin{array}{l}\text { Hernia on the } \\
\text { opposite side }\end{array}$ & $0(0)$ & $2(4)$ & 0.092 \\
\hline Acute pain & 20 (28.6) & $18(36)$ & 0.388 \\
\hline Chronic pain & $2(2.9)$ & $5(10)$ & 0.100 \\
\hline Testicular pain & $0(0)$ & $0(0)$ & NA \\
\hline $\begin{array}{l}\text { Pain during } \\
\text { intercourse }\end{array}$ & $0(0)$ & $0(0)$ & NA \\
\hline Dysuria & $1(1.4)$ & $2(4)$ & 0.374 \\
\hline
\end{tabular}

* Not applicable.

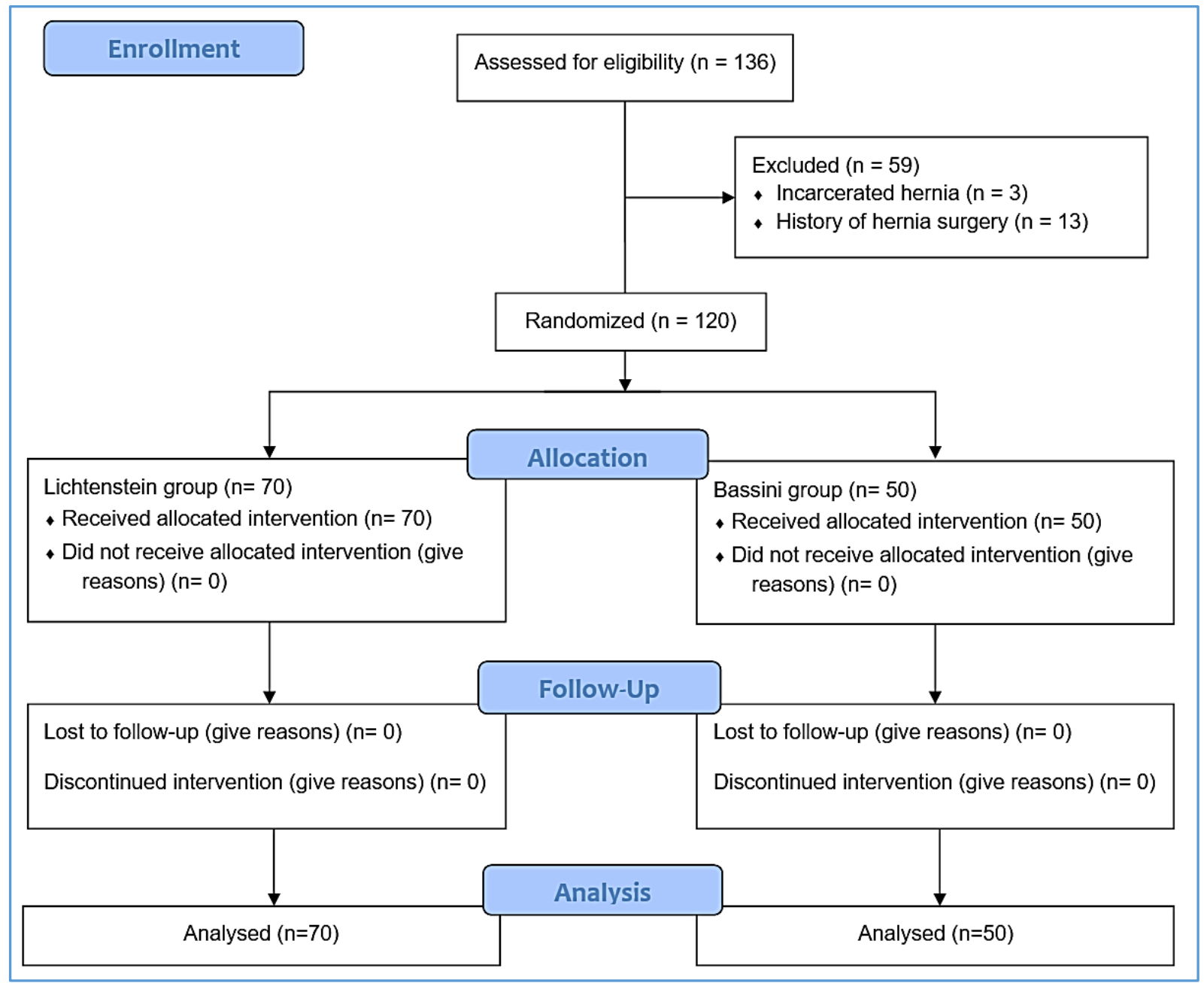

Figure 1. CONSORT Diagram 


\section{DISCUSSION}

Repairing the inguinal hernia with mesh is stated to be a safer method with less compilations compared with the method without mesh. This surgery can be done under general anaesthesia and it is possible to quickly return to normal activity. In Naeem et al's study,(14) for example $98 \%$ of the patients were discharged on the first hospital day. Some surgeons consider it as an outpatient surgery. This surgery is a good choice for the patients living in deprived and remote areas and need to get back to work early.

In our study, the time to get back to work and also the hospitalisation time were almost similar together in both Bassini and Lichtenstein groups and no significant differences were seen between them. In their study, Tavassoli et al(15) who compared the two methods of Lichtenstein and laparoscopic Totally Extraperitoneal (TEP) hernia repair, the time to resume the living activity in TEP group was $3.16 \pm 3.1$ days, significantly less than that in Lichtenstein group which was $6.6 \pm 3.05$ days. These times were both longer than our experience in the present study.

Our results are in agreement with Naeem et al's results,(14) that is $96 \%$ of the patients did not have any complications during hospitalisation. Also, no patients experienced recurrence. In opposite to our results about recurrence, the study by Askarpour et al.(16) On 120 patients, of whom $37.5 \%$ underwent Bassini method and $42.5 \%$ underwent Lichtenstein technique with mesh indicated that $16 \%$ of the Bassini group and 3\% of the Lichtenstein group reported recurrence totally, stating a significant decrease in recurrence among Bassini's patients. The cause of recurrence could be probably remaining the function of transversalis fascia.

Inguinal pain is one of the most important complications that is complained by the patients undergoing all hernioplasty methods and can lead to decrease in quality of life and make problem in daily living activity. Wide range of studies have been conducted about clinical expression and diagnosis of chronic inguinal pain after hernioplasty, but its real aetiopathology has remained unknown. Bhat(17) stated that $40 \%$ of the modified Bassini herniorrhaphy patients had mild pain, whereas this rate was $28 \%$ in the Lichtenstein group. The predictive factors for the chronic pain include psychiatric factors, the primary postoperative pain, neurological injury during surgery and type of surgery technique (Open versus Laparoscopic).(18,19) Different pain syndromes may occur in inguinal region which usually result from scar tissue, reaction to prosthesis or involvement of nerve with suture materials during herniorrhaphy.(20) About the severity of pain, mean VAS pain score significantly differed between the two groups of Lichtenstein and Bassini and Lichtenstein group subjects had less score.

In a study, Mohebbi et al(20) compared the post-operative complications between the three groups of herniorrhaphy, Rives and Lichtenstein. The results showed that postoperative infection, haematoma and pain were not significantly different, but the post-operative pain one year after the surgery and rate of recurrence were significantly more in the herniorrhaphy method than in others and the authors proposed the Lichtenstein as the method with less complications. In our study, infection and haematoma were only seen in 1 and 2 patients, respectively, and no significant differences were observed between the surgeries in terms of these complications. Wound infection is one of the common complications in hernia repair with mesh. Some researchers reported high rates of infection for this method. $(3,21)$

Khoshnevis et al(22) compared the post-operative complications between the three methods of Lichtenstein, Bassini and Bassini with mesh. They stated that no significant differences existed in the recurrence and other postoperative complications between Bassini and Lichtenstein methods and both of them were appropriate for inguinal hernia repair. It was also stated that Bassini is used more frequently, because of its cheaper cost. In the mentioned study, method of Bassini with mesh was not recommended acceptably due to more post-operative complications like inguinal pain and being more expensive.(22) Similarly, our study showed low rate of post-operative complications and both of Lichtenstein and Bassini methods were appropriate for inguinal hernia repair.

\section{CONCLUSION}

According to the results, Lichtenstein and Bassini techniques had close outcomes and rate of post-operative complications did not differ between them. This was in contrast to our hypothesis that Lichtenstein method has significantly better outcome than Bassini method. Our results proposed that both Lichtenstein and Bassini methods can be considered as safe choices for treatment of inguinal hernia.

\section{ACKNOWLEDGEMENT}

We would like to thank the Vice Chancellor for Research, of Babol University of Medical Sciences, for supporting our study.

\section{REFERENCES}

[1] Daoud IM, Dunn K. Groin pain etiology: the inguinal hernia, the occult inguinal hernia, and the lipoma. In: Jacob, BP, eds. The SAGES manual of groin pain. Springer 2016:49-58.

[2] Monson JR, Weiser MR. Sabiston Textbook of surgery. The biological basis of modern surgical practice. Springer 2008.

[3] MacFadyen BV, Mathis CR. Inguinal herniorrhaphy: complications and recurrences. Seminars in Laparoscopic Surgery 1994;1(2):128-40.

[4] Nilsson E, Kald A, Anderberg B, et al. Hernia surgery in a defined population: a prospective three year audit. Eur J Surg 1997;163(11):823-9.

[5] Ohene-Yeboah M, Beard JH, Frimpong-Twumasi B, et al. Prevalence of inguinal hernia in adult men in the Ashanti Region of Ghana. World J Surg 2016;40(4):806-12.

[6] Hallén M, Sevonius D, Holmberg $H$, et al. Low complication rate and an increasing incidence of surgical repair of primary indirect sliding inguinal hernia. Langenbecks Arch Surg 2016;401(2):215-22.

[7] Latheef AA, Ramlal RV, Ansar P. Comparison of Lichtenstein's tension free mesh repair with GPRVSStoppa s repair for bilateral inguinal hernia. J Evolution Med Dent Sci 2017;6(26):2164-8.

[8] Nasir IUI, Iftikhar M, Aslam R, et al. Chronic postoperative pain following groin hernia repair: a comparison between nerve preservation and nerve excision. KJMS 2014;7(2):226-30. 


\section{Jemds.com}

[9] Friis-Andersen $\mathrm{H}$, Bisgaard $\mathrm{T}$. The Danish inguinal hernia database. Clin Epidemiol 2016;8:521-24.

[10] Werner MU, Kongsgaard UE. I. Defining persistent post-surgical pain: is an update required? $\mathrm{Br} J$ Anaesth 2014;113(1):1-4.

[11] Treede RD, Rief W, Barke A, et al. A classification of chronic pain for ICD-11. Pain 2015;156(6):1003-7.

[12] Voutilainen A, Pitkäaho T, Kvist T, et al. How to ask about patient satisfaction? The visual analogue scale is less vulnerable to confounding factors and ceiling effect than a symmetric Likert scale. J Adv Nurs 2016;72(4):946-57.

[13] Schulz KF, Altman DG, Moher D. CONSORT 2010 statement: updated guidelines for reporting parallel group randomised trials. Trials 2010;11:32.

[14] Naeem A, Durrani NS, Jamshed A. Lichtenstein repair of inguinal hernia. KJMS 2014;7(2):199-201.

[15] Tavassoli A, Ghamari MJ, Esmaily H. Repair of inguinal hernia: a comparison between extraperitoneal laparoscopy and Lichtenstein open surgery. Tehran Univ Med J 2010;68(3):168-74.

[16] Askarpour S, Hafezi M, Shooshtari SM, et al. Clinical characteristics and rate of recurrence of inguinal hernia in Imam Khomeini and Razi hospitals of Ahvaz. Jundishapur Sci Med J 2007;6(1):10-5.

\section{Original Research Article}

[17] Bhat SS. Comparative study between Lichtenstein tension-free and modified Bassini's repair for inguinal hernias. J Evolution Med Dent Sci 2017;6(45):3503-6.

[18] Pittau MR, Contu P, D'Aloj E. Chronic pain following inguinal hernia repair: Assessment of quality of life and medico-legal aspects. Ann Ital Chir 2013;84(3):357-63.

[19] Shekhar C, Asif S, Hingora OM. Laparoscopic totally extraperitoneal (TEP) repair versus Lichtenstein $\mathrm{s}$ repair for inguinal hernia - a prospective study. J Evolution Med Dent Sci 2017;6(25):2065-8.

[20] Mohebbi H, Mehrvarz S, Moosazvi-Naeini S, et al. Comparison of quality of life and complications after different treatment methods of one-sided inguinal hernia. Kowsar Medical Journal 1388;14(4):217-21.

[21] Brunicardi F, Andersen D, Billiar T, et al. Schwartz's principles of surgery. 10th edn. McGraw-Hill 2014.

[22] Khoshnevis J, Ziirakzadeh H, Falah A. Comparison of results and complications of Bassini, Lichtenstein and Bassini with mesh techniques in inguinal hernia repair at Shohadaye Tajrish Hospital, Tehran. Iranian Journal of Surgery 2013;21(2):20-8. 